\title{
Marfan Syndrome with Bilateral Retinal Detachment
}

\author{
Chunu Shrestha ${ }^{1}$, Varun Shrestha ${ }^{1}$.
}

${ }^{1}$ Nepal Eye Hospital, Tripureshwor, Kathmandu, Nepal.

\begin{abstract}
Marfan syndrome is an autosomal dominant systemic disorder of connective tissue. Marfan syndrome affects most organs and tissues, especially the skeleton, lungs, eyes, hearts, and the large blood vessels. It was described by Antoine Marfan in 1896. Aortic root aneurysm and ectopia lentis are the cardinal features. In the absence of family history, the presence of these two manifestations is sufficient for confirmatory diagnosis of Marfan syndrome. Patients with ocular manifestations should be screened for cardiac involvement to support diagnosis. Retinal detachment is a potentially dangerous manifestation for its sight threatening nature. There is no cure for Marfan syndrome, so treatment focuses on managing the symptoms and reducing the risk of complications. Recent advances in diagnosis, improved surgical technique and application of prophylaxis has contributed in preservation of sight in such patients.
\end{abstract}

Keywords: marfan syndrome, retinal detachment, autosomal dominant.

\section{INTRODUCTION}

Marfan syndrome (MS) is an autosomal dominant systemic disorder of connective tissue. MS is characterized by abnormal biosynthesis of fibrillin-1 which is the major constituent of microfibrils due to mutation of FBN-1, gene on human chromosome $15 .{ }^{1}$

In 1876, E. William and Antoine Marfan described the disease for the first time ${ }^{2}$. About $50 \%$ of the patients with Marfan syndrome are diagnosed by an ophthalmologist; some individuals may present with isolated ocular signs suggestive of this syndrome ${ }^{3}$.

The main ocular features of MS, all of which can result in decreased vision include bilateral ectopialentis, myopia and retinal detachment ${ }^{4}$. Although retinal detachment in case of Marfan syndrome has no special treatment issues, it has greater chance of recurrence. ${ }^{5}$

\section{CASE REPORT}

A tall 28 year old woman presented with blurred vision in both eyes for 1 month. The severity of blurring of vision was more in left eye. The presenting visual acuity in right eye was $6 / 24$ and hand movement perception of left eye. Slit lamp examination of anterior segment revealed clear cornea in both eyes with corneal diameter in right eye $14 \mathrm{~mm}$ vertically, 15 $\mathrm{mm}$ horizontally and left eye $14 \mathrm{~mm}$ vertically, $15 \mathrm{~mm}$ horizontally which showed megalocornea. Both eyes angle were deep without any opposition to cornea in either side. The pupil was $2 \mathrm{~mm}$ in size in both eyes which did not dilate with dilating drop and there was no evidence of relative afferent pupillary defect. There was absence of lens in both eyes giving a jet black appearance of the pupil. There was bilateral posterior lens dislocation in the vitreous cavity with right eye subtotal Rhegmatogenous Retinal detachment with macula on and left eye total Rhegmatogenous Retinal detachment with macula off.

\section{Correspondence:}

Dr. Chunu Shrestha

Nepal Eye Hospital, Tripureshwor, Kathmandu

Email:chunu20@hotmail.com 
The axial length is $30.30 \mathrm{~mm}$ right eye and $31.33 \mathrm{~mm}$ left eye which showed axial myopia. The keratometry reading in right eye is $\mathrm{KI}-8.93 \mathrm{~mm}$; $\mathrm{K} 2-8.10 \mathrm{~mm}$ and in left eye is $\mathrm{K} 1-8.93 \mathrm{~mm}, \mathrm{~K} 2-8.29 \mathrm{~mm}$.

There was no history of trauma to the eyes or head and she is previously non diabetic and non hypertensive. No previous history of any ocular ailment was present and she was not suffering from myopia. She was 170 $\mathrm{cm}$ tall and her arm span length was $183 \mathrm{~cm}$ (arm span: height $>1.07$ );reduced upper to lower body segment ratio, which was 0.73 (normal-0.86).

General examination showed presence of pectus carinatum with long slender fingers and high arched palate with malocclusion of teeth with generalized joint laxity. Echocardiography showed presence of dilated aortic root, mild aortic regurgitation.

The thumb and the little finger overlapped well while wrapping the other wrist (positive walker's sign) and when enclosed within the clenched fist, the thumb protruded beyond the ulnar border (positive steinberg sign).

Figure 1. Aracnodactyly

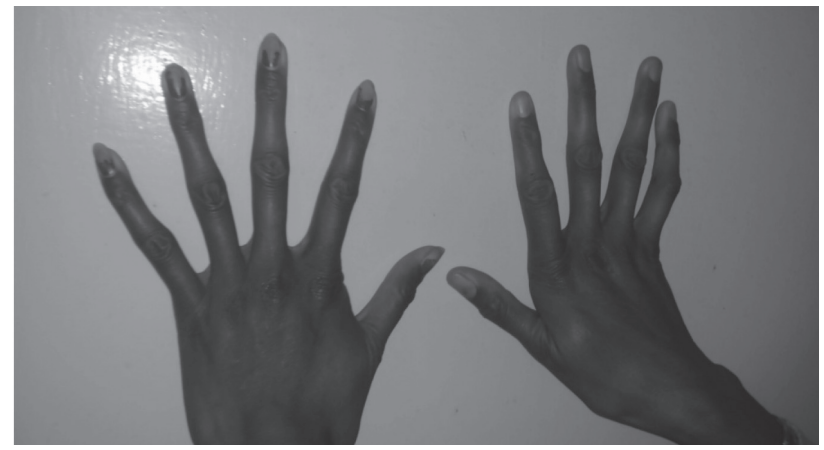

Figure 2: Positive walker's sign

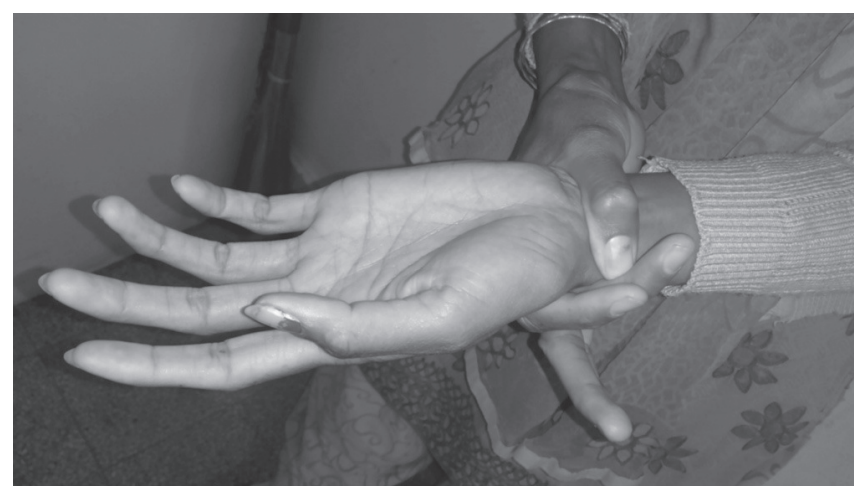

Figure 3: Steinberg's sign

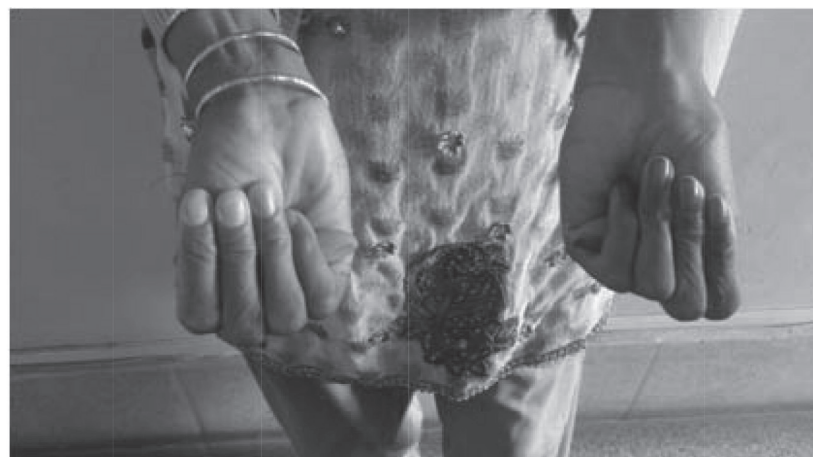

Routine blood tests including peripheral blood counts, renal and liver function test, serum electrolytes were within normal limits. Chest X-ray showed no bullae or pneumothorax. Echocardiography showed dilated aortic root and mild aortic regurgitation.

Patient was treated with LE Band buckle, lensectomy, pars planavitrectomy ( $23 \mathrm{G})$, endolaser and intraocular tamponade with silicon oil. Patient made a slow but uneventful recovery with best corrected visual acuity of $6 / 9$ (with correction of $+4.00 \mathrm{DS} /-2.00$ at $90^{\circ}$ ) in $\mathrm{RE}$ and $6 / 24$ (with correction of $+4.50 \mathrm{DS} /-1.00$ at $90^{\circ}$ ) in LE after 3 months.

\section{DISCUSSION AND REVIEW OF LITERATURE}

The diagnosis of Marfan syndrome as per the revised Ghent criteria was made, which states that the combined presence of aortic root dilatation or dissection and ectopia lentis is considered to be equivocal manifestations for diagnosis of Marfan syndrome.

Retinal detachment continues to be the most serious ocular complication, occurring in $5-11 \%$ of patients. However, the incidence of retinal detachment increases to $8-38 \%$ in the presence of ectopia lentis.

There is also a high incidence of bilateral retinal detachment, occurring in up to $69 \%$ of patients with retinal detachment. Retinal detachment in Marfan syndrome generally occurs in the mid-twenties, predominantly affects men, and can be missed on routine examination owing to poor visualization secondary to small pupils and lens abnormalities ${ }^{6-8}$.

The reasons for developing retinal detachment in Marfan syndrome are unstable subluxated or dislocated lens capsule exerting traction on the vitreous base, 
MJSBH July-December 2014|Vol 13| Issue 2

leading to small tears or holes in the retinal periphery and globe elongation and axial myopia which is common in Marfan syndrome are associated with early vitreous liquefaction and posterior vitreous detachment, retinal thinning, lattice degeneration and peripheral breaks- all of which predispose patients to multiple large or even giant retinal breaks. ${ }^{7,8}$

Genetic disorder leads to social, emotional and financial stress. Screening test can be used as an early diagnostic tool for genetic diseases which is simple, moderately expensive and noninvasive. Worldwide, there are many support groups for individuals with Marfan syndrome. In Nepal such support groups should be initiated so that we can encourage patients and their families to seek guidance, counseling and emotional comfort by meeting with others afflicted with this condition.

To conclude posterior lens dislocation with Rhegmatogenous Retinal detachment in Marfan syndrome can have good visual outcome if surgery is carried out early and with recent surgical technique.

\section{REFERENCES}

1. Robinson PN, Godfrey M. The molecular genetics of Marfan syndrome and related microfibrillopathies. J Med Genet 2000;37:9-25.http://dx.doi.org/10.1136/jmg.37.1.9

2. Judge DP, Dietz HC (2005) Marfan's syndrome. Lancet366:1965-1976.

3. Nemet AY, Assia EI, Apple DJ, Barequet IS. Current concepts of ocular manifestations in Marfan syndrome. SurvOphthalmol. 2006;51:561-75.http://dx.doi. org/10.1016/j.survophthal.2006.08.008

4. Dean JCS, Bradshaw NE, Haites NE et al. The Scottish Clinical Guidelines And Integrated Care Pathways ForMarfan syndrome. Genisys, 2003.

5. Dean JC. Marfan syndrome: Clinical diagnosis and management. Eur J Hum Genet. 2007;15:724-33.http:// dx.doi.org/10.1038/sj.ejhg.5201851

6. Lee Y, AngCL.Results of retinal detachment surgery in Marfan syndrome in Asians. Retina. 2003;2:24-9.http:// dx.doi.org/10.1097/00006982-200302000-00004

7. Sharma T, Gopal L, Shanmugam MP et al. Retinal detachment in Marfan syndrome: clinical characteristics and surgical outcome. Retina 2002;22:423-8.http://dx.doi. org/10.1097/00006982-200208000-00005

8. Remulla JF, Tolentino FI. Retinal detachment in Marfan's syndrome.IntOphthalmolClin 2001;41:235-40.http://dx.doi. org/10.1097/00004397-200110000-00021 